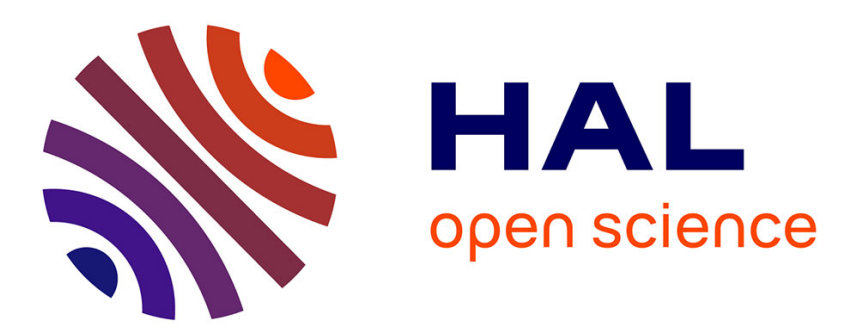

\title{
Optical and electrical anisotropy of ordered layers of rigid core semiconductor - dithienothiophene derivative
}

T. Marszalek, E. Dobruchowska, Julien Jung, J. Ulanski, M. Melucci, G. Barbarella

\section{- To cite this version:}

T. Marszalek, E. Dobruchowska, Julien Jung, J. Ulanski, M. Melucci, et al.. Optical and electrical anisotropy of ordered layers of rigid core semiconductor - dithienothiophene derivative. European Physical Journal: Applied Physics, 2010, 51 (3), pp.33208. 10.1051/epjap/2010107 . hal-00618491

\author{
HAL Id: hal-00618491 \\ https://hal.science/hal-00618491
}

Submitted on 2 Sep 2011

HAL is a multi-disciplinary open access archive for the deposit and dissemination of scientific research documents, whether they are published or not. The documents may come from teaching and research institutions in France or abroad, or from public or private research centers.
L'archive ouverte pluridisciplinaire HAL, est destinée au dépôt et à la diffusion de documents scientifiques de niveau recherche, publiés ou non, émanant des établissements d'enseignement et de recherche français ou étrangers, des laboratoires publics ou privés. 


\title{
Optical and electrical anisotropy of ordered layers of rigid core
}

\section{semiconductor - dithienothiophene derivative}

T. Marszalek ${ }^{1}$, E. Dobruchowska ${ }^{1}$, J. Jung ${ }^{1}$, J. Ulanski ${ }^{1}$, M. Melucci $^{2}$, and G. Barbarella ${ }^{2}$

1 Department of Molecular Physics, Technical University of Lodz, Zeromskiego 116, 90-924 Lodz, Poland, tel.: +(48)42-631-3205, fax: +(48)42-631-32-18 e-mail: tomasz.marszalek@p.lodz.pl

2 Consiglio Nazionale Ricerche, CNR-ISOF, Via P. Gobetti 101, I-40129 Bologna, Italy

Received: date / Revised version: date

\begin{abstract}
Preparation of highly oriented layers of organic semiconductor - dithienothiophene derivative is described. The layers were obtained by zone-casting technique - a solution based one step method that does not require the use of preoriented substrates. Unidirectional alignment of the dithienothiophene derivative molecules in the zone-cast layers was confirmed by absorption and photoluminescence polarized spectra. Anisotropy of electrical properties was characterised by means of anisotropy of charge carrier mobility in field effect transistors (FETs). The FET devices were fabricated in bottom contacts - bottom gate configuration with the channel lengths parallel and perpendicular to the crystal growth direction, respectively. The FET mobility determined in the direction parallel to the zone-casting direction is ca. 1 order of magnitude higher than those in the perpendicular direction.
\end{abstract}

PACS. 78.55.Kz Solid organic materials - 78.66.Qn Polymers; organic compounds - 85.30.Tv Field effect devices

\section{Introduction}

The organic field effect transistor performance depends strongly on two factors: charge carrier delocalization on the organic semiconducting molecule and position of the molecules with respect to each other [1]. Most often, crysSend offprint requests to: tomasz.marszalek@p.lodz.pl talline organic semiconductors create low dimensional systems, where high charge carrier mobility is due to either 1D $\pi-\pi$ stacks or $2 \mathrm{D}$ transfer integrals. However, single crystals are difficult to grow and to handle, thus there is a need to elaborate methods of preparation of large area anisotropic layers made of oriented quasi-1D long crys- 
talline wires. Among methods allowing to prepare such as ordered structures, these based on solution processes are highly valued because of their simplicity and low cost [2]. One of them is the so called zone-casting technique [34]. The method consists in continuous deposition of the solution onto a moving substrate. The driving force of the molecular alignment is the solute concentration gradient in the meniscus region, where the molecules become gradually less mobile, and when the critical concentration is reached they adapt ordered structures. In this paper, we present study on anisotropy of optical and electrical properties of highly oriented thin layers of dithienothiophene derivative - 2,6-bis(5-hexyl-thiophene)-ditieno[3,2b;2,3-d]thiophene (DTT5), obtained by the zone-casting technique.

\section{Experimental procedures}

DTT5, shown in Fig. 1, was synthesized by microwaveassisted Suzuki coupling, as previously described $[5,6]$. The compound exhibits liquid crystalline properties. Large area ordered layers $\left(10 \mathrm{~cm}^{2}\right)$ of DTT5 were obtained from toluene solution (1 mg/1 ml) continuously supplied, through a flat nozzle, with a speed of $10 \mu \mathrm{m} / \mathrm{s}$ onto substrates moving with a speed of $50 \mu \mathrm{m} / \mathrm{s}$. Substrates and nozzle were thermally stabilized at $72{ }^{\circ} \mathrm{C}$ and $77^{\circ} \mathrm{C}$, respectively. Glass and highly n-doped Si wafers with $50 \mathrm{~nm}$ of thermally grown $\mathrm{SiO}_{2}$ were used as the substrates. The quality of the obtained layers was examined by Polarized Optical Microscopy (POM, Biolar microscope, PZO) and Atomic Force Microscopy (AFM, SOLVER PRO scanning probe microscope, NT-MDT). Optical anisotropy was examined using UV-Vis-NIR spectrometer (Cary 5000, Varian) and spectrofluorometer (Fluorog FL3-11, Jobin-Yvon). Anisotropy of electrical properties was investigated in terms of anisotropy of charge carrier mobility $\left(\mu_{F E T}\right)$ in field effect transistors (FETs). The FET devices based on DTT5 were fabricated in bottom contacts - bottom gate configuration, which was imposed by liquid crystalline properties of the semiconductor. Golden source and drain contacts were vacuum evaporated on the top of $\mathrm{SiO}_{2}$ layer. The devices have channel length $10 \mu \mathrm{m}$ and channel width/channel length ratios of 10000 and 2000 for the channel length parallel and perpendicular to the casting direction, respectively.

\section{Results and discussion}

\subsection{Optical anisotropy of the DTT5 zone-cast layers}

POM and AFM images revealed that layers exhibit similar and reproducible orientation on entire, large area (Fig. 2). One can observed long crystalline needles grown along the casting direction, what proves that the DTT5 molecules exhibit tendency for unidirectional crystallization in the applied zone-casting conditions. The layers zone cast on glass substrate show birefringence when observed between crossed polarizers, indicating homogenous molecular alignment within the crystallites. Thus, one can assume that obtained crystallites are in fact uniaxial crystals. When the crystal optic axis is parallel to the polarization plane of the polarizer, almost no light is transmitted through the sample (Fig. 2a), however when the crystals are oriented 
at $45^{\circ}$ with respect to the polarization planes of both polarizers, maximum transmission of light is observed (Fig. 2b). Also the polarized UV-Vis absorption spectra indicate an unidirectional alignment of the DTT5 molecules.

On Fig. 3a the polarized spectra (solid line and dotted line) are compared with the spectrum obtained without polarizer (dashed line). One can see that in the polarized spectra different absorption bands are visible, while the unpolarized spectrum shows all the bands. The spectra obtained for solid state are blue shifted with respect to that in solution (not shown here), in which the dominant maximum is placed at around $400 \mathrm{~nm}$. This suggests that formation of H-aggregates with cofacially aligned molecules occurs in the solid state [7]. Additionally, this could explain also very strong polarization dependence of the absorption spectra. In particular, the appearance of bands in the range of $325-375 \mathrm{~nm}$, when the light is polarized approximately parallel to the crystals long axes may be understood as a result of the strong coupling between the stacked molecules. Fig. 3b demonstrates the polarized photoluminescence (PL) spectra obtained for the oriented DTT5 layer, after excitation with the light wavelength of $330 \mathrm{~nm}$. Two broad, overlapping peaks, at around $510 \mathrm{~nm}$ and $540 \mathrm{~nm}$, can be observed in all recorded PL spectra, but their intensity is much higher when the polarization plane of the analyzer is perpendicular to the zone-casting direction (it means that the emitted light is polarized perpendicularly to the crystal grow direction). Assuming, that the molecules are arranged cofacially, one can conclude that in this case the spectra are dominated by the emission from the individual molecules. The calculated polarization ratio, which is defined as $\mathrm{P}=[\mathrm{I} \|-\mathrm{I} \perp] /[\mathrm{I} \|+$ $\mathrm{I} \perp$ ] (where: $\mathrm{I} \|$ and $\mathrm{I} \perp$ are the intensities of the emission components polarized parallel and perpendicularly with respect to the exciting light when polarized perpendicularly to the casting direction), is larger than $60 \%$ over the spectral range from $505 \mathrm{~nm}$ to $545 \mathrm{~nm}$. It confirms high degree of molecular order in the obtained DTT5 zone-cast layers.

\subsection{Electrical anisotropy of the DTT5 zone-cast layers}

The anisotropy of electrical properties of the zone-cast DTT5 layers manifests in very different characteristics of the FETs with the channel oriented parallel and perpendicularly to the casting direction. As one can see on Fig. 4 , for the same source-drain voltage $\left(\mathrm{U}_{D S}\right)$ and the same gate-source voltage $\left(\mathrm{U}_{G S}\right)$ the current intensity between the source and drain contacts $\left(\mathrm{I}_{D S}\right)$ is much higher along the casting direction (Fig. 4a) then in the perpendicular direction (Fig. 4b). The charge carrier mobility calculated on a basis of the transfer characteristics is $\mu_{F E T}=0.0005$ $\mathrm{cm}^{2} / \mathrm{Vs}$ along the crystal grow direction, and at least 10 times lower $\left(\mu_{F E T}<0.00005 \mathrm{~cm}^{2} / \mathrm{Vs}\right)$, in the perpendicular direction; the $\mathrm{ON} / \mathrm{OFF}$ ratio $>10^{4}$, is similar in both cases. The charge carrier mobility obtained for the devices with channel length parallel to the casting direction is one order of magnitude higher than that reported for the FETs based on the thermally evaporated and drop-cast layers of the same compound [8]. 


\section{Conclusions}

The zone-casting techniques allows to produce large area, uniformly oriented thin layers of dithienothiophene derivative in which the molecules are cofacially arranged and form quasi $1 \mathrm{D}$ crystalline, parallel stacks resulting in high anisotropy of electronic properties of the layers.

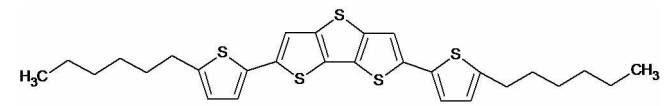

Fig. 1. The chemical structures of 2,6-bis(5-hexyl-thiophene)ditieno[3,2-b;2,3-d] thiophene (DTT5).
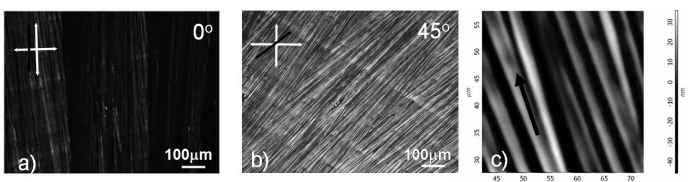

Fig. 2. POM images of zone cast DTT5 layers (a, b) obtained in the transmission mode for the sample on glass substrate and AFM image (c) for the sample on $\mathrm{Si} / \mathrm{SiO}_{2}$ substrate. Grey arrows indicate casting direction, black arrows orientation of polarization planes of polarizer and analyzer.
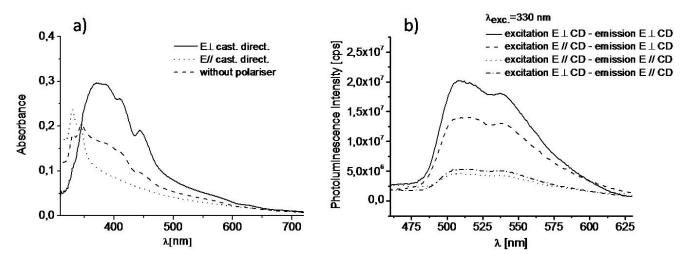

Fig. 3. Polarized absorption spectra (a) and polarized photoluminescence spectra (b) of DTT5 zone-cast on glass; E\| polarization plane of the polarizer parallel to the zone-casting direction, $\mathrm{E} \perp$ polarization plane the polarizer perpendicular to the zone-casting direction, CD - casting direction.
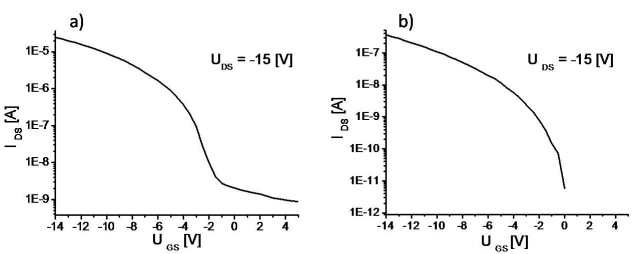

Fig. 4. Transfer characteristics for FETs made of DTT5 zonecast on $\mathrm{Si} / \mathrm{SiO}_{2}$ with channel length parallel (a) and perpendicular to the casting direction (b).

\section{References}

1. C.D. Dimitrakopoulos, D.J. Mascaro, IBM Journal of Research and Development 45, (2001) 11.

2. H. Nishimura, M. Iizuka, S. Kuniyoshi, M. Nakamura, K. Kudo, K. Tanaka, Electron. Comm. Jap.: Part 2 87, (2004) 18.

3. P. Miskiewicz, M. Mas-Torrent, J. Jung, S. Kotarba, I. Glowacki, E. Gomar-Nadal, D.B. Amabilino, J. Veciana, B. Krause, D. Carbone, C. Rovira, J. Ulanski, Chem. Mater. 18, (2006) 4724 .

4. C.M. Duffy, J.W. Andreasen, D.W. Breiby, M.M. Nielsen, M. Ando, T. Minakata, H. Sirringhaus, Chem. Mater. 20, (2008) 7252 .

5. A. Suzuki, J. Organomet. Chem. 576, (1999) 147.

6. M. Melucci, G. Barbarella, M. Zambianchi, P. Di Pietro, A. Bongini, J. Org. Chem. 69, (2004) 4821.

7. S. Zang, Y. Guo, H. Xi, Ch. Di, J. Yu, K. Zheng, R. Liu, X. Zhan, Y. Liu, Thin Solid Films 517, (2009) 2968.

8. M. Melucci, L. Favaretto, Ch. Bettini, M. Gazzano, N. Camaioni, P. Maccagnani, P. Ostoja, M. Monari, G. Barbarella, Chem. Eur. J 36, (2007) 10007.

This work was supported partially by NAIMO Integrated Project, No NMP 4-ct-2004-500355 and by NoE PolyNet UE ICT 214006. 